\title{
Effects of UV-Vis Irradiation on Vanadium Etioporphyrins Extracted from Crude Oil and the Role of Nanostructured Titania
}

\author{
Debra Jene Kirkconnell Reyes, ${ }^{1}$ Andrés García Saravia Ortiz de Montellano, ${ }^{1}$ \\ Rudy Amilcar Trejo Tzab, ${ }^{2}$ Gerko Oskam, ${ }^{1}$ and Juan José Alvarado Gil ${ }^{1}$ \\ ${ }^{1}$ Department of Applied Physics, CINVESTAV-Unidad Mérida, Antigua Carretera a Progreso Km. 6, 97310 Mérida, YUC, Mexico \\ ${ }^{2}$ Facultad de Ingeniería Química, Universidad Autónoma de Yucatán, Periférico Norte Km. 33.5, Tablaje Catastral 13615, \\ Col. Chuburná de Hidalgo Inn, 97310 Mérida, YUC, Mexico
}

Correspondence should be addressed to Debra Jene Kirkconnell Reyes; debrakirkconnell@gmail.com

Received 14 December 2013; Revised 7 February 2014; Accepted 8 February 2014; Published 2 April 2014

Academic Editor: Wei Xiao

Copyright (C) 2014 Debra Jene Kirkconnell Reyes et al. This is an open access article distributed under the Creative Commons Attribution License, which permits unrestricted use, distribution, and reproduction in any medium, provided the original work is properly cited.

\begin{abstract}
The role of UV-irradiation on oil and its derivatives is particularly important for analyzing the degradability of specific oil compounds. Also, nanostructured- $\mathrm{TiO}_{2}$ is one of the most promising photocatalysts so it is expected to be useful in their degradation. However the complexity of crude oil, as well as that of the reactions involved, is such that the effect of the presence of $\mathrm{TiO}_{2}$ under illumination is not well understood. In this paper, the influence of UV-Vis irradiation on vanadium etioporphyrins, extracted from crude oil from Dos Bocas, Tabasco, Mexico, is studied using UV-Vis spectrophotometry in the absence and presence of nanostructured $\mathrm{TiO}_{2}$ or nitrogen-doped $\mathrm{TiO}_{2}$ modified with copper $\left(\mathrm{N}-\mathrm{TiO}_{2} / \mathrm{Cu}\right)$. It is shown that the addition of water shortens the time to start photodegradation. However, once this process has initiated, the system enters a second stage, that is very similar for samples with or without water. It is also shown that the use of $\mathrm{N}-\mathrm{TiO}_{2} / \mathrm{Cu}$ induces an important delay in the initiation of the porphyrins' photodegradation process. Additionally, it has been found that the presence of $\mathrm{TiO}_{2}$ in samples extracted with water induces a small reduction in the photodegradation duration and, hence, that $\mathrm{TiO}_{2}$ can catalyze the degradation of petroporphyrins.
\end{abstract}

\section{Introduction}

The many substances forming part of crude oil can have a limited lifetime due to various external factors. One of the most important degrading factors affecting oil is UV light. The photochemical transformation of a given molecule into lower molecular weight fragments occurs usually via an oxidation process [1]. Photodegradation of petroleum products both in laboratory and the field have been extensively explored [2]. In particular, the effect of photolysis has been studied for a variety of pure hydrocarbons under solar and simulated solar conditions $[3,4]$. It has been shown that, depending on temperature and using light intensities in the range from 200 to $750 \mathrm{~W} / \mathrm{m}^{2}$, some water-soluble compounds such as naphthalenes and phenanthrenes can degrade rapidly. In contrast, other aromatic compounds such as alkylated benzenes did not exhibit photodegradation under these conditions [4].

In general, it is important to know under which conditions certain substances remain in the oil, stable or not, under UV illumination. This can be helpful in the development of efficient methods to attend the problems generated by spills, and the vulnerability of specific components is also important for commercial or industrial purposes [5-7]. However, a large number of substances still remain to be explored and understood under diverse conditions.

Porphyrins are among the most interesting substances forming part of crude oil. In particular, the specific chemical structure of the porphyrins provides a fingerprint of the origin of the oil. They are mainly present as vanadyl and nickel chelated compounds, although metal-free porphyrins have also been isolated from immature sediments [8]. 
The identification and characterization of metalloporphyrins in crude oils and source rock are of fundamental interest within a geochemical context, because they may provide a better understanding of the geochemical origin of the petroleum via diagenetic and catagenetic oil formation and maturation of organic matter. Another interesting feature related to metalloporphyrins is their significant presence in heavy crude oil, which can cause problems as these metals have a deleterious effect on the hydrogenation catalysts used in upgrading and refining processes [9].

A common material used in cleaning the environment is titania $\left(\mathrm{TiO}_{2}\right)$, one of the best-known photocatalytic materials due to its high photoactivity and photostability. The photocatalytic activity of titania depends on its physical properties, such as crystal structure, surface area, particle size, particle shape, among others [10]. One of the main disadvantages of $\mathrm{TiO}_{2}$ is its large band gap of $3.2 \mathrm{eV}$ (anatase), which implies that it only absorbs UV light, corresponding to about $5 \%$ of the solar spectrum. However, nanostructured $\mathrm{TiO}_{2}$ is expected to be useful in the degradation of crude oil as well as some of their compounds [11]. On the other hand, there are strong limitations in degrading crude oil; maybe the most important limitation is related to the opacity of crude oil to UV light, which does not allow light to successfully degrade oil even if adequate photocatalysts are present. When crude oil is mixed with solvents, a partial extraction of some components occurs; however, the effects of light and catalysts on the extracts are not well understood. Oil extracts containing porphyrins are common, and the analysis of their degradability using $\mathrm{TiO}_{2}$ nanoparticles is an interesting challenge.

In recent years, it has been shown that the photocatalytic action of $\mathrm{TiO}_{2}$ can be enhanced by impregnation with metals such as copper. For example, the degradation of methylene blue is accelerated using nitrogen-doped $\mathrm{TiO}_{2}$ modified with copper $\left(\mathrm{N}-\mathrm{TiO}_{2} / \mathrm{Cu}\right)$ nanomaterials prepared by plasma discharge techniques in the presence of metallic copper and gaseous nitrogen [12]. In this paper, the effects of UV-Vis irradiation on crude oil extracts containing petroporphyrins are analyzed in the absence and presence of nanostructured $\mathrm{TiO}_{2}$. In addition, the degradation of the metalloporphyrins in the presence of $\mathrm{N}-\mathrm{TiO}_{2} / \mathrm{Cu}$ nanomaterials is determined, and the role of water in the degradation processes is considered.

\section{Materials and Methods}

For the experiments we used Maya crude oil from Dos Bocas, Tabasco, Mexico, which is an oil with ${ }^{\circ}$ API $=21.57,3.4$ wt $\%$ sulfur, and $0.32 \mathrm{wt} \%$ nitrogen. The following two extraction methods were used.

In the first method, $1.7 \mathrm{~mL}$ of heavy crude oil was mixed with $60 \mathrm{~mL}$ of acetone in a beaker, and then the following procedure was performed.

(a) The mixture was stirred during 2 minutes, using a Sonics ultrasonic vibrating cell (model TM VCX130PB) operating at $10 \mathrm{~W}$. (b) The obtained sample was covered with a black metallic foil and a plastic bag and left for 24 hours to obtain the extract.

(c) The supernatant, now with a yellow color, was transferred to a second beaker labeled COE (crude oil extract).

The second extraction procedure was performed by mixing $1.7 \mathrm{~mL}$ of heavy crude oil in a beaker with $60 \mathrm{~mL}$ of acetone and $5 \mathrm{~mL}$ of distilled water, maintaining the proportion $12: 1$ of acetone to distilled water. Afterwards, the sample was treated following the same procedure as described in steps (a), (b), and (c). The solution obtained in the second extraction procedure was labeled COEW (crude oil extract with water). Additionally, a standard solution was prepared by dissolving $0.1 \mathrm{mg}$ of vanadium (IV) etioporphyrin III oxide $\left(\mathrm{C}_{32} \mathrm{H}_{36} \mathrm{~N}_{4}\right.$ OV Santa Cruz Biotechnology, CAS number 15709-03-2) in $60 \mathrm{~mL}$ of acetone.

Two types of nanostructured $\mathrm{TiO}_{2}$ powder were used, both based on Degussa P25: pure $\mathrm{TiO}_{2}$ and $\mathrm{N}-\mathrm{TiO}_{2} / \mathrm{Cu}$. This last compound was obtained by a plasma treatment of Degussa P25 in a nitrogen atmosphere in the presence of metallic copper [12]. Figure 1 shows the XPS analysis as well as the $\mathrm{X}$-ray diffraction patterns of the $\mathrm{N}-\mathrm{TiO}_{2} / \mathrm{Cu}$ material. $\mathrm{X}$-ray diffraction exhibits the well-known proportion of $80 \%$ anatase and 20\% rutile in titania Degussa P25 but it does not have the sensitivity to detect the presence of copper in the material. However there are small differences between both spectra that can be observed; some peaks are slightly displaced while others are wider or higher, but all of them are closely related to the ones observed in untreated Degussa P25 (see Figure 1(a)). These small changes can be related to changes in the nanoparticles' size due to the copper impregnation process.

In contrast, XPS measurements are able to detect the presence of copper in $\mathrm{N}^{-\mathrm{TiO}_{2}} / \mathrm{Cu}$ (see Figure 1(b)); in these measurements two bands associated with copper, as well as the characteristic bands of $\mathrm{TiO}_{2}$ (Degussa P25) and a band related to nitrogen, can be observed. Additional analyses have shown that the plasma-treated samples contain about $4.4 \mathrm{wt} \%$ of nitrogen and $0.4 \%$ of copper [12].

Using the COE and COEW extracts, a set of samples was prepared by adding $25 \mathrm{mg}$ of $\mathrm{TiO}_{2}$ or $\mathrm{N}-\mathrm{TiO}_{2} / \mathrm{Cu}$, labeled COE-TiO ${ }_{2}, \mathrm{COE}-\left(\mathrm{N}-\mathrm{TiO}_{2} / \mathrm{Cu}\right), \mathrm{COEW}-\mathrm{TiO}_{2}$, and COEW$\left(\mathrm{N}-\mathrm{TiO}_{2} / \mathrm{Cu}\right)$, respectively. These samples were submitted to an additional mixing process using a Sonics ultrasonic vibrating mixer cell operated at $10 \mathrm{~W}$ for 2 minutes and left to settle for 60 minutes with the samples covered to prevent evaporation. For all the solutions, $\mathrm{COE}, \mathrm{COEW}, \mathrm{COE}-\mathrm{TiO}_{2}$, COEW- $-\mathrm{TiO}_{2}, \mathrm{COE}-\left(\mathrm{N}-\mathrm{TiO}_{2} / \mathrm{Cu}\right)$, and COEW- $\left(\mathrm{N}-\mathrm{TiO}_{2} / \mathrm{Cu}\right)$ aliquots of about $10 \mathrm{~mL}$ were taken from the beakers and labeled as "time zero" experiments. The remaining solution in each one of the beakers was then poured into an Erlenmeyer flask integrated with a cooling system and placed at $400 \mathrm{rpm}$ using magnetic stirring. For the photodegradation studies, the light of a $1000 \mathrm{~W}$ Xenon lamp (Oriel 6269), operated at $400 \mathrm{~W}$, was used to illuminate the Erlenmeyer reaction vessel from above. This lamp provided $370 \mathrm{~W} / \mathrm{m}^{2}$ on the surface of the sample, with most of the intensity in the visible region 


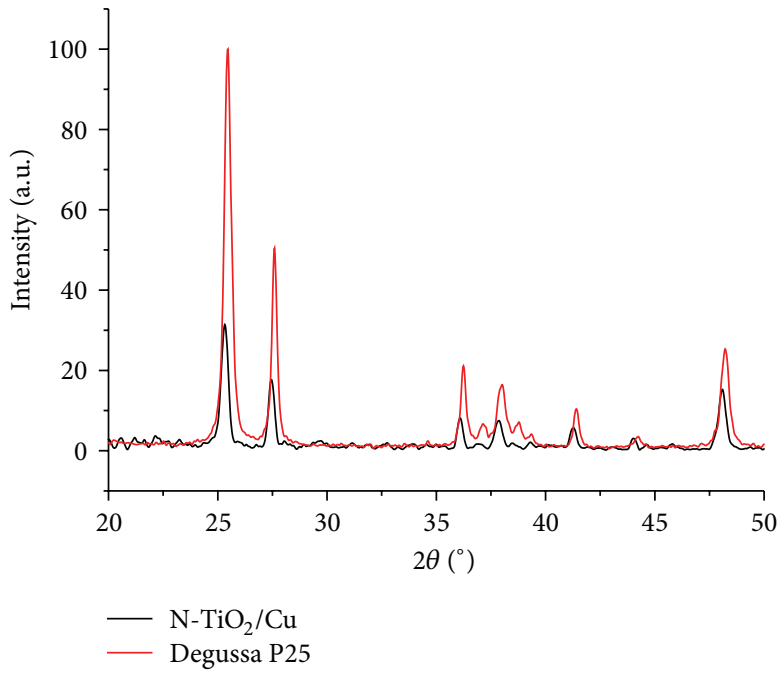

(a)
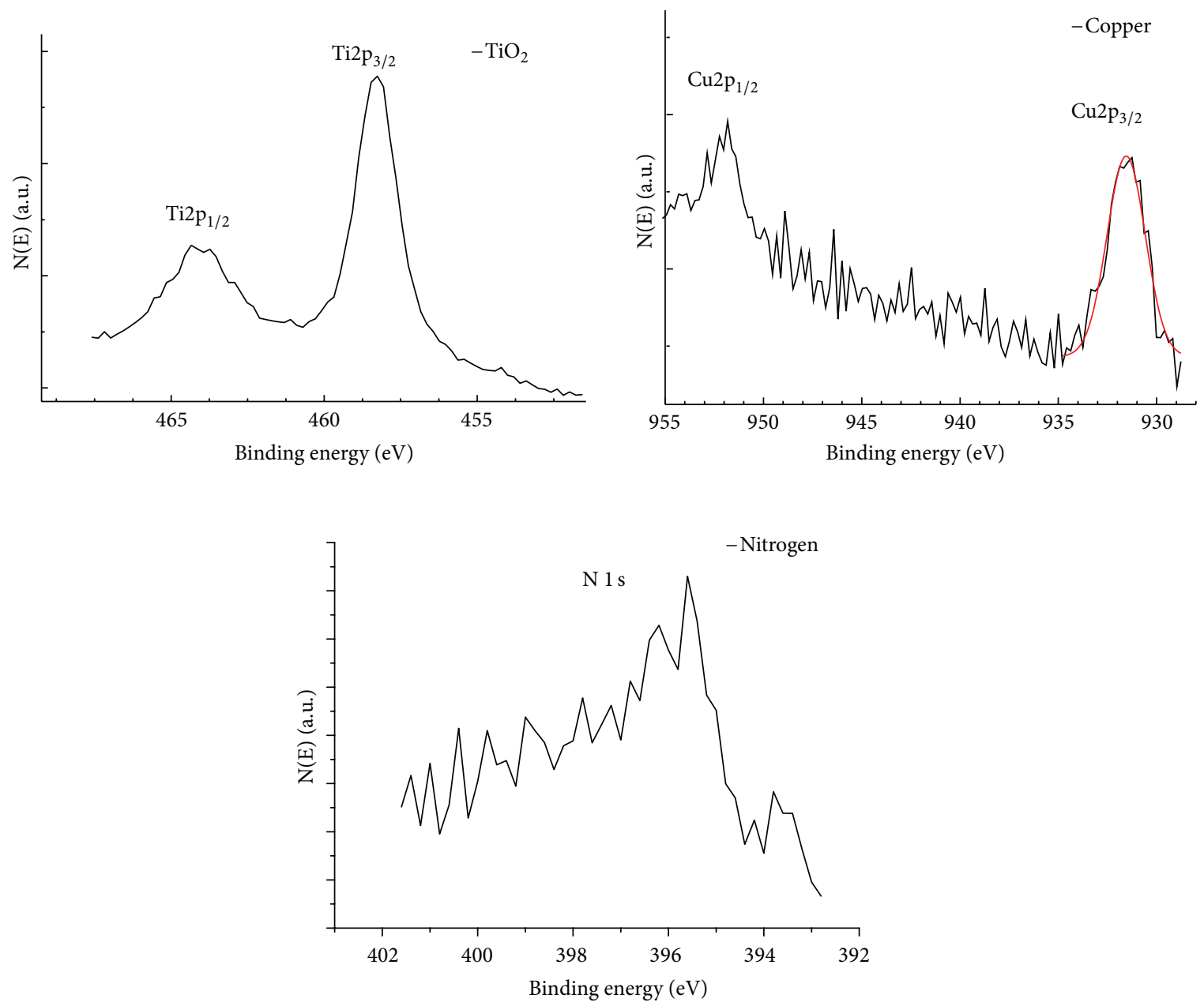

(b)

Figure 1: (a) X-ray diffraction spectra of $\mathrm{TiO}_{2}$ (Degussa P25) and $\mathrm{N}-\mathrm{TiO}_{2} / \mathrm{Cu}$. (b) XPS of $\mathrm{N}-\mathrm{TiO}_{2} / \mathrm{Cu}$. 


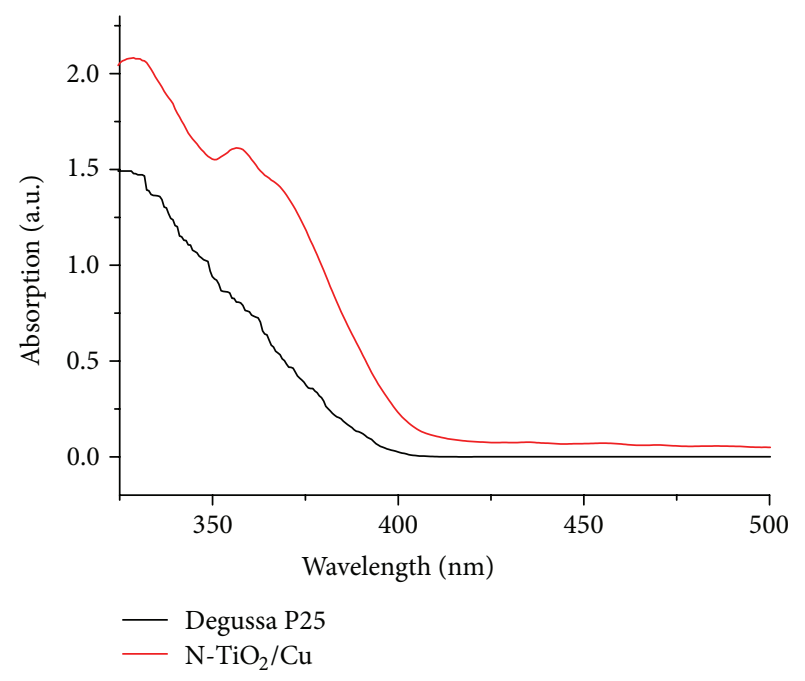

Figure 2: Absorption of $\mathrm{TiO}_{2}$ and $\mathrm{N}-\mathrm{TiO}_{2} / \mathrm{Cu}$ obtained from diffuse reflectance measurements using the Kubelka-Munk method.

of light, a good emission of UVA and UVB light, and a very low fraction of UVC. During irradiation the samples in the jacketed flask were maintained at a temperature of $30^{\circ} \mathrm{C}$ using a circulating water system. Aliquots of $10 \mathrm{~mL}$ were taken from the Erlenmeyer flask every hour for five hours and transmission optical spectra for the samples were measured in quartz cuvettes using a fiber UV-Vis spectrophotometer in the range from $200 \mathrm{~nm}$ to $1100 \mathrm{~nm}$ using an AvaSpec-2048 fiber optic spectrometer with a deuterium lamp as the light source.

\section{Results and Discussion}

Figure 2 shows the absorption spectra, obtained from diffuse reflectance measurements on the powder by applying the Kubelka-Munk method, of the Degussa P25 and $\mathrm{N}-\mathrm{TiO}_{2} / \mathrm{Cu}$ powders used in the experiments, and an absorption increment for $\mathrm{N}-\mathrm{TiO}_{2} / \mathrm{Cu}$ in visible light can be observed.

The COE and COEW samples were illuminated over a period of 5 hours, and Figure 3 shows the corresponding $\mathrm{UV}-\mathrm{Vis}$ spectra obtained before illumination (time zero) and after every hour. Before irradiation the spectra for COE and COEW samples show a broad band from $220 \mathrm{~nm}$ to $450 \mathrm{~nm}$ with three small peaks at $300 \mathrm{~nm}, 350 \mathrm{~nm}$, and $400 \mathrm{~nm}$ and also a shoulder at $250 \mathrm{~nm}$. Additionally, two smaller bands can be observed at $530 \mathrm{~nm}$ and $569 \mathrm{~nm}$. The spectra remain largely unchanged upon irradiation; however, as illustrated in the insets, the peaks at $530 \mathrm{~nm}$ and $569 \mathrm{~nm}$ disappear upon prolonged illumination indicating a degradation process.

The COE- $\mathrm{TiO}_{2}$ and $\mathrm{COEW}-\mathrm{TiO}_{2}$ as well as the COE-(N$\left.\mathrm{TiO}_{2} / \mathrm{Cu}\right)$ and COEW- $\left(\mathrm{N}-\mathrm{TiO}_{2} / \mathrm{Cu}\right)$ samples show the same bands as the samples without $\mathrm{TiO}_{2}$; however, the shoulder at $250 \mathrm{~nm}$ appears more clearly, as illustrated in Figures 4 and 5. Similar to the samples without $\mathrm{TiO}_{2}$, the two bands at $530 \mathrm{~nm}$ and $569 \mathrm{~nm}$ are also observed.

It is well known that crude oil contains petroporphyrins [13] so it is possible that the small bands at $530 \mathrm{~nm}$ and
$569 \mathrm{~nm}$ correspond to such type of compounds. Comparing the experimental UV-Vis spectra from the crude oil extracts with databases of spectra for petroporphyrins, we conclude that the vanadium etioporphyrins are the best fit for our crude oil samples. In Figure 6, the UV-Vis spectrum of a standard solution of vanadium etioporphyrin in acetone is presented. In this spectrum, the wide band from $200 \mathrm{~nm}$ to $270 \mathrm{~nm}$ is due to acetone [14] while a narrow band appearing at $414 \mathrm{~nm}$ can be identified as the Soret band. Additionally, two smaller bands are clearly observed at $530 \mathrm{~nm}$ and $569 \mathrm{~nm}$. From these results, it can be inferred that the peaks of the spectra of our extracts appearing at $530 \mathrm{~nm}$ and $569 \mathrm{~nm}$ correspond to vanadium etioporphyrins as previously reported for crude oil from the same geographic location [9].

The UV-Vis spectrum of petroporphyrins show bands that correspond to a strong electronic transition to the second excited state $\left(S_{0} \rightarrow S_{2}\right)$ at about $400 \mathrm{~nm}$ (the Soret or B band) and a weak transition to the first excited state $\left(S_{0} \rightarrow\right.$ $S_{1}$ ) at about $550 \mathrm{~nm}$ (the Q band). Internal conversion from $S_{2}$ to $S_{1}$ is rapid and, as a consequence, fluorescence is only detected from $S_{1}$. The B and the Q bands both arise from $\pi-\pi^{*}$ transitions and can be explained by considering the four frontier orbitals (HOMO and LUMO orbitals) (the Gouterman four orbital model) [15]. Gouterman's “fourorbital" model of the $\pi-\pi^{*}$ transitions in porphyrins is firmly established as a simple unifying theory of porphyrin spectra. It provides parametric expressions for the frequencies and intensities of the $\alpha-\beta(\mathrm{Q})$ and Soret (B) bands of the porphyrin chromophore. Spectral shifts caused by systematic variation of ring substituents and changes of the encapsulated metal ion, axial ligation, or even dimer formation have successfully been rationalized based on these grounds $[16,17]$. The electronic transition to the higher energy mixed state, the $S_{2}$ state, is strongly allowed, whereas the electronic transition to the lower energy mixed state, the $S_{1}$ state, is only weakly allowed. The band in the UV-Vis absorption spectrum due to a transition to the $S_{2}$ state is the Soret band, and the band due to a transition to the vibrationless $S_{1}$ state is the $\alpha$ band. The greater the degree of mixing, the less intense the $\alpha$ band relative to the Soret band. In the UV-visible spectrum of porphyrin, there is also a vibronic band, the $\beta$ band, which appears at slightly lower wavelengths than the $\alpha$ band. The $\beta$ band is due to transitions to higher vibrational levels in the $S_{1}$ state and serves as a normalization band in porphyrin absorption spectra [15]. In summary, the three characteristic bands appearing in the spectra of the nonirradiated samples correspond to the bands of vanadium etioporphyrins: at $407 \mathrm{~nm}$ the Soret band and the $\beta$ and $\alpha$ bands at $533 \mathrm{~nm}$ and $572 \mathrm{~nm}$, respectively [18]. When the intensity of the $\alpha$ band is larger than that of the $\beta$ band, the metal forms a stable squareplanar complex with the porphyrin [19].

In order to determine the concentration of vanadium etioporphyrins in our samples, we prepared dilutions of the standard solution (vanadium IV etioporphyrin III oxide) and determined the absorbance as a function of concentration. The relationship between the absorbance $(A)$ and concentration $(C)$, according to the Lambert-Beer law, is given by $A=\varepsilon d C$, where $d(\mathrm{~cm})$ and $\varepsilon\left(\mathrm{L} \mathrm{cm}^{-1} \mathrm{mg}^{-1}\right)$ are the thickness and extinction coefficient of the sample, 


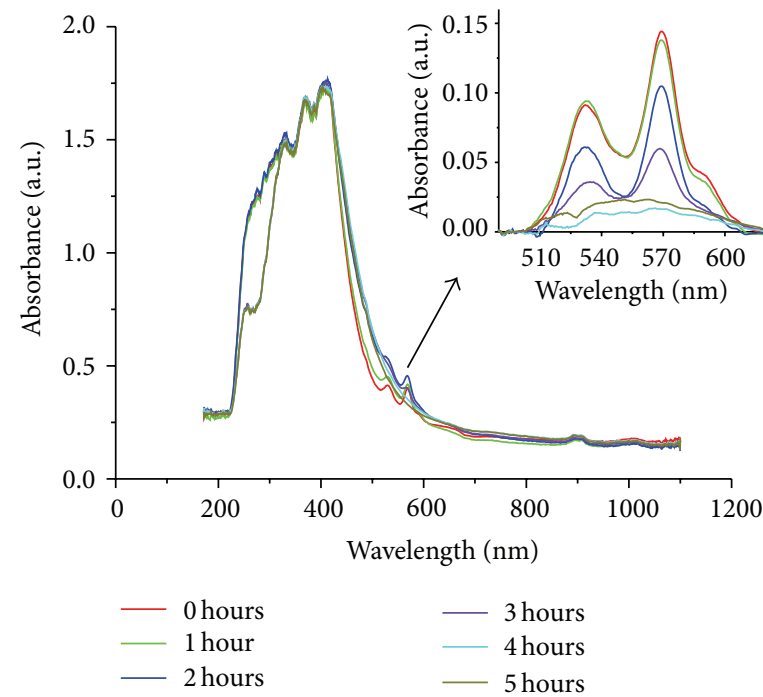

(a)

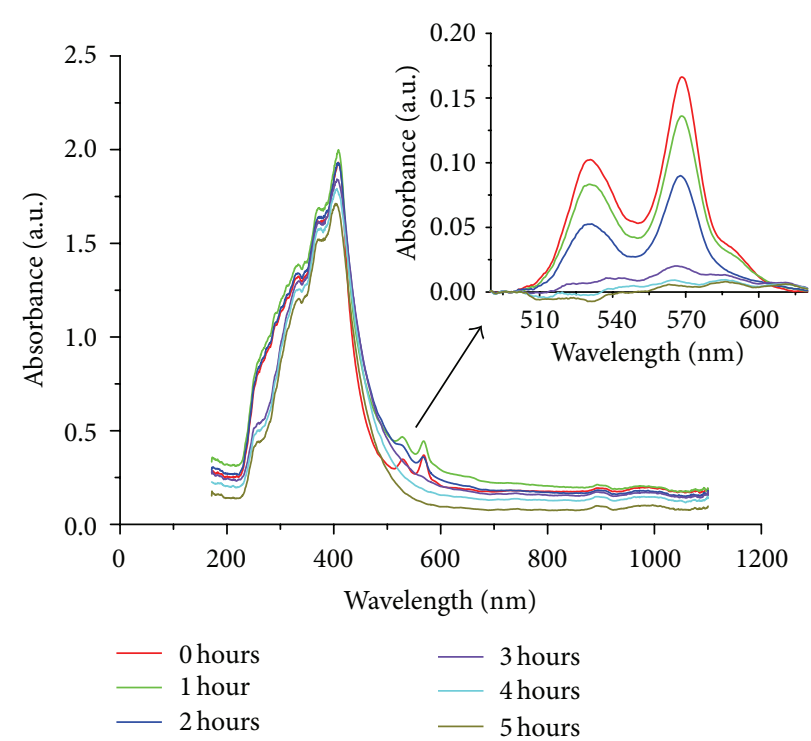

(b)

FIGURE 3: UV-Vis absorbance spectra as a function of illumination time of the crude oil extracts: (a) COE and (b) COEW. The insets show the bands observed at $530 \mathrm{~nm}$ and $569 \mathrm{~nm}$ with the background subtracted.

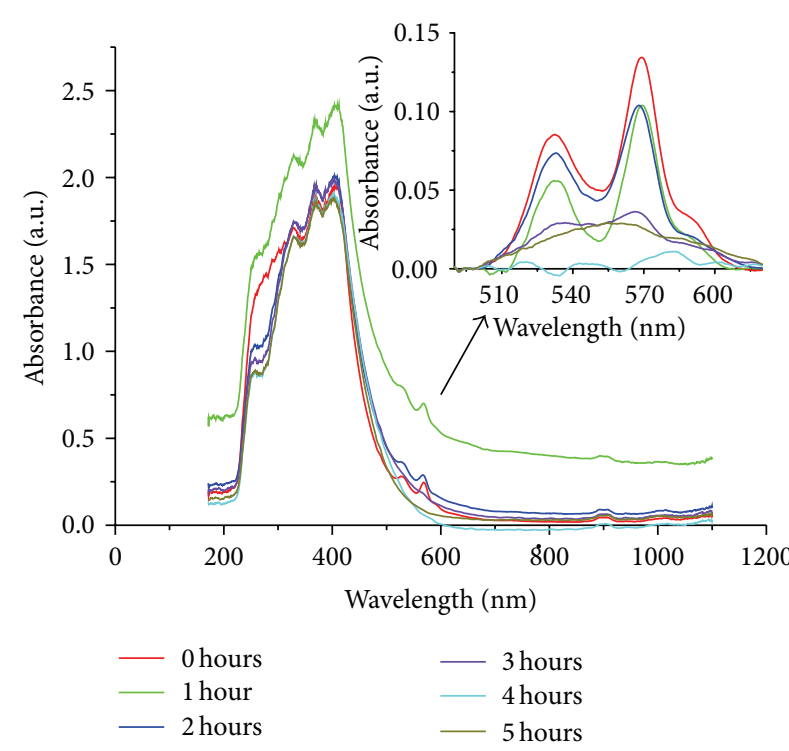

(a)

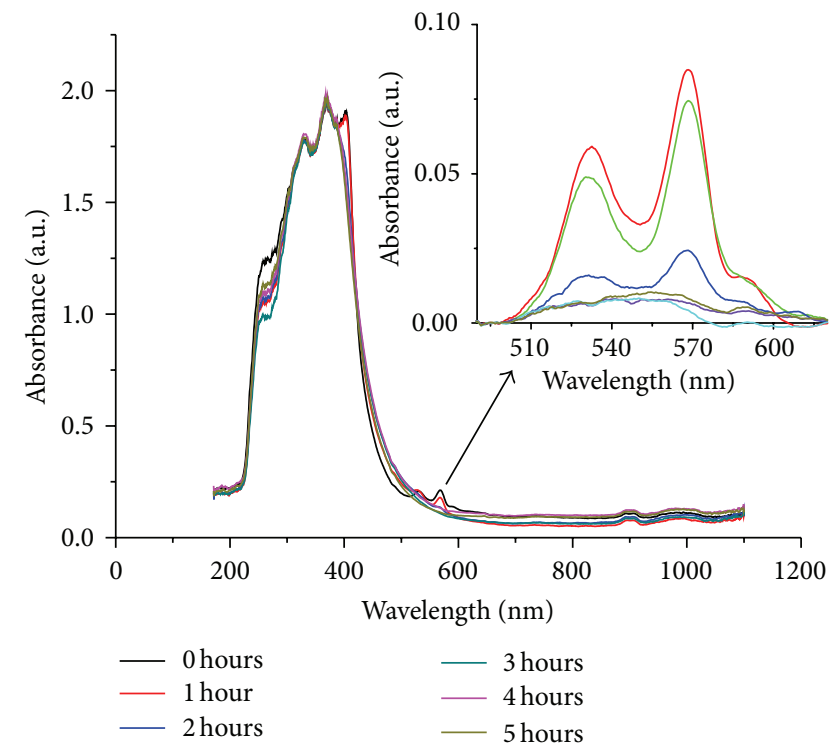

(b)

FIgURE 4: UV-Vis absorbance spectra as a function of illumination time in the presence of the $\mathrm{TiO}_{2}$ nanomaterial with the crude oil extracts: (a) $\mathrm{COE}-\mathrm{TiO}_{2}$ and (b) $\mathrm{COEW}-\mathrm{TiO}_{2}$. The insets show the bands observed at $530 \mathrm{~nm}$ and $569 \mathrm{~nm}$.

respectively. In Figure 7, the absorbance maximum of the $\alpha$ peak versus concentration is presented, in which the fit of the experimental data provides a value of $0.116 \mathrm{~L} \mathrm{~cm}^{-1} \mathrm{mg}^{-1}$ for the extinction coefficient.

Using these results, the concentration of the vanadium etioporphyrin in our COE can be estimated as being $3.8 \mathrm{mg} / \mathrm{L}$, which is in agreement with generally observed concentrations in crude oil from the oil from the same geographical location [9].
Due to the UV-Vis irradiation treatment, there are changes in intensity in various bands in the spectra; however, we will focus our attention on the bands in the range from $500 \mathrm{~nm}$ to $620 \mathrm{~nm}$ because they are associated directly with the vanadium etioporphyrins. In order to perform a nonambiguous analysis of the bands appearing in all spectra, we separated the $\alpha$ and $\beta$ bands absorbance from the main background absorbance by fitting a cubic spline in the smooth region from $425 \mathrm{~nm}$ to $750 \mathrm{~nm}$, excluding 


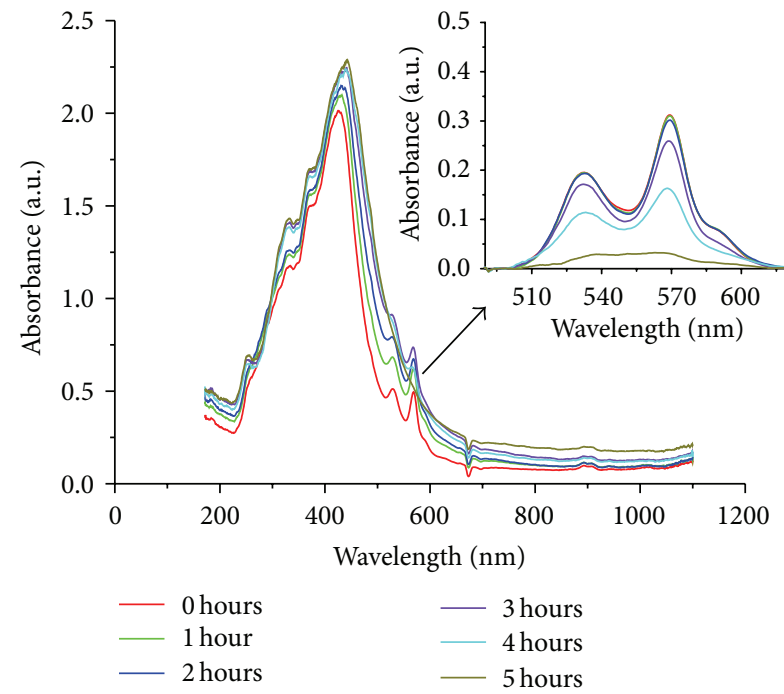

(a)

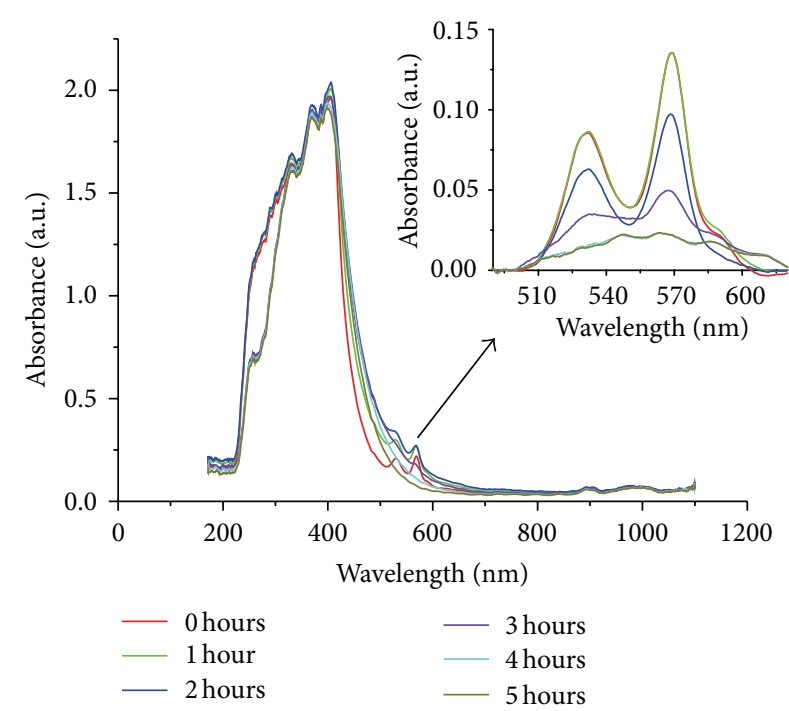

(b)

FIgURE 5: UV-Vis absorbance spectra as a function of illumination time in the presence of the $\mathrm{N}-\mathrm{TiO}_{2} / \mathrm{Cu}$ nanomaterial with the crude oil extracts: (a) COE- $\left(\mathrm{N}-\mathrm{TiO}_{2} / \mathrm{Cu}\right)$ and (b) COEW- $\left(\mathrm{N}-\mathrm{TiO}_{2} / \mathrm{Cu}\right)$. The insets show the bands observed at $530 \mathrm{~nm}$ and $569 \mathrm{~nm}$ with the background subtracted.

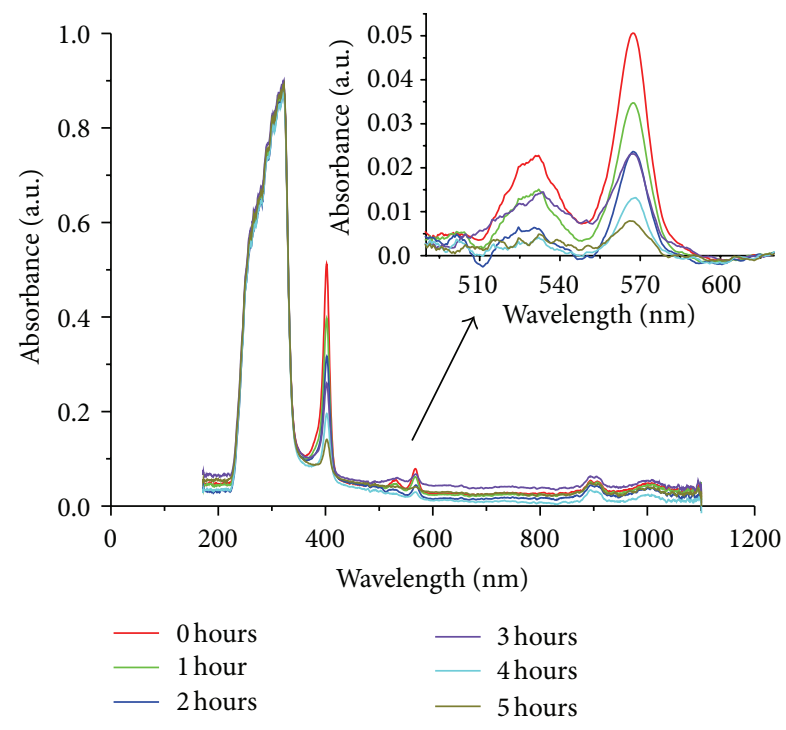

FIGURE 6: UV-Vis absorbance spectra as a function of irradiation time of the standard vanadium etioporphyrins solution in acetone. The insets show the bands observed at $530 \mathrm{~nm}$ and $569 \mathrm{~nm}$ with the background subtracted.

the region from $500 \mathrm{~nm}$ to $625 \mathrm{~nm}$ and then subtracting this background from the measured absorbance. The result of this background removal is shown in the insets of Figures 3 to 6 . After one hour of UV-Vis irradiation, a noticeable decrease in intensity of the $\alpha$ and $\beta$ bands in all the samples is observed; however, the kinetics depend on the extraction method and the presence and type of catalyst. In order to characterize the results obtained when irradiating with UVVis light, the area under the curves of the $\alpha$ and $\beta$ bands was

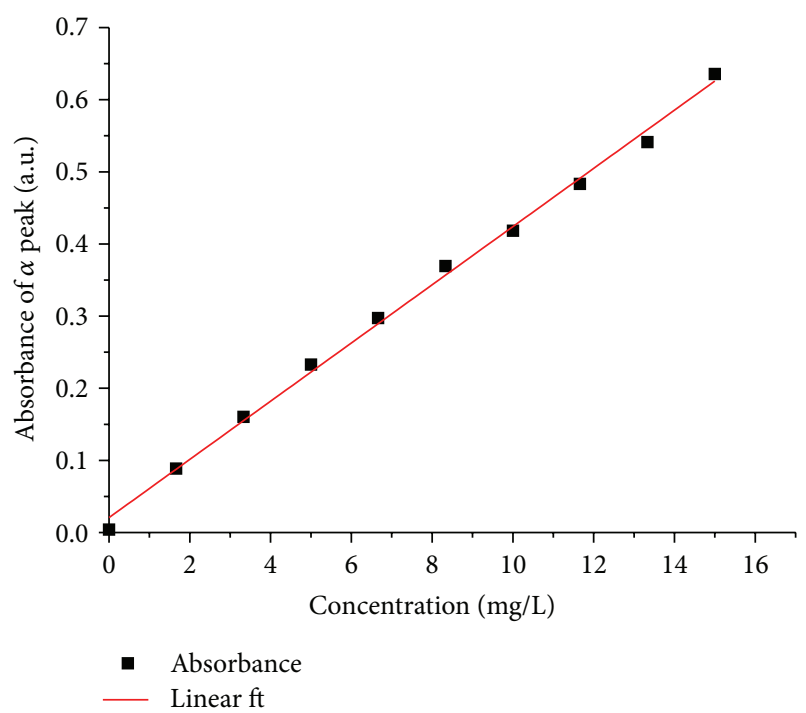

FIGURE 7: Calibration curve for the vanadium (IV) etioporphyrin III oxide solution in acetone using the height of the absorbance of the $\alpha$ peak as a function of the concentration.

determined. Figure 8 shows the areas under the peaks versus the irradiation time. It can be seen that in all cases the $\alpha$ and $\beta$ peaks disappear after several hours of irradiation, but that the time needed for this degradation process depends strongly on the presence of water, $\mathrm{TiO}_{2}$, and $\mathrm{N}-\mathrm{TiO}_{2} / \mathrm{Cu}$. As a general trend, it can be observed that the presence of water shortens the degradation time of the vanadium etioporphyrins, both for the measurements with and those without $\mathrm{TiO}_{2}$ or $\mathrm{N}$ $\mathrm{TiO}_{2} / \mathrm{Cu}$. 


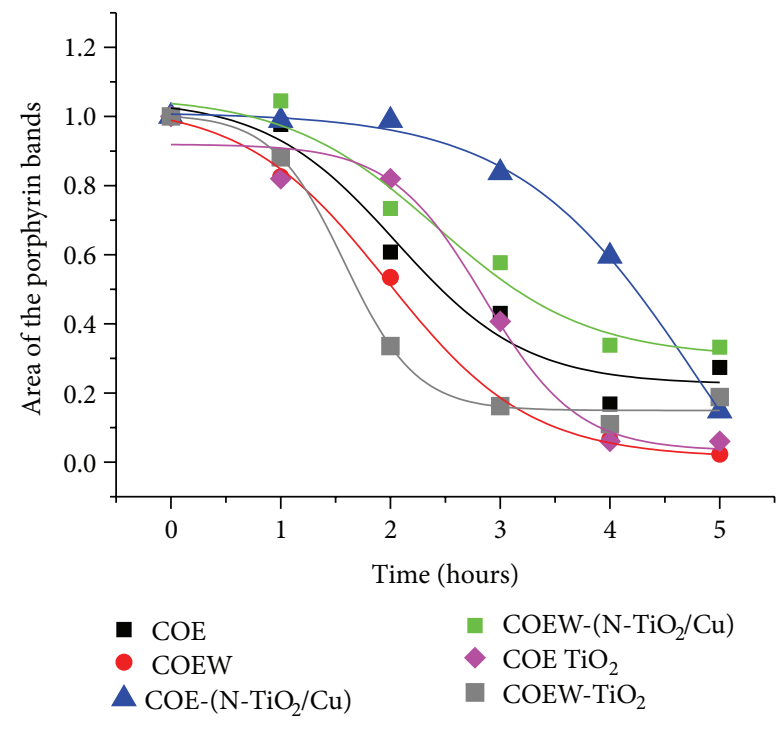

Figure 8: Time evolution of the area of the $\alpha$ and $\beta$ bands as a consequence of the photodegradation.

The results for samples of crude oil extracts to which $\mathrm{N}-\mathrm{TiO}_{2} / \mathrm{Cu}$ was added $\left(\mathrm{COE}-\left(\mathrm{N}-\mathrm{TiO}_{2} / \mathrm{Cu}\right)\right.$ and COEW- $(\mathrm{N}-$ $\left.\mathrm{TiO}_{2} / \mathrm{Cu}\right)$ ) show interesting effects: the samples without water, $\mathrm{COE}-\left(\mathrm{N}-\mathrm{TiO}_{2} / \mathrm{Cu}\right)$, show the smallest degradation rate of all samples. In the case of the COEW- $\left(\mathrm{N}-\mathrm{TiO}_{2} / \mathrm{Cu}\right)$ samples, the degradation rate is faster than for the COE- $(\mathrm{N}-$ $\mathrm{TiO}_{2} / \mathrm{Cu}$ ) samples, but slower than for all other samples. Total disappearance of the $\alpha$ and $\beta$ peaks in this case takes more than 5 hours of irradiation.

The experimental data of the area under both bands corresponding to the petroporphyrins can be analyzed using a sigmoidal fit of the following form:

$$
\text { Area }=B_{2}+\frac{\left(B_{1}-B_{2}\right)}{1+e^{\left(t-t_{0}\right) / \Delta \tau}}
$$

where $B_{1}$ is the initial (maximum) value and $B_{2}$ is the final (minimum) value. The time $t_{0}$ corresponds to the point at which the slope of the curve changes (inflection point) corresponding to where the maximum rate of change of the process is reached; $t_{0}$ measures the time at which half of the process has occurred and is useful to determine if a given factor delays or impedes the process. In this sense it is useful in defining the start of a given kinetic process. The parameter $\Delta \tau$ measures the duration of the process around $t_{0}$, in such a way that for an interval $4 \Delta \tau, 95 \%$ of the process has occurred. Based on this, the time for the photodegradation resulting from a given treatment, $T$, can be found using the formula $T=t_{0}+2 \Delta \tau$. The continuous lines in Figure 8 correspond to the results of the fits of the experimental data to (1), and the results for the parameters are presented in Figure 9.

Comparing the samples $\mathrm{COE}$, $\mathrm{COE}-\left(\mathrm{N}-\mathrm{TiO}_{2} / \mathrm{Cu}\right)$, and $\mathrm{COE}-\mathrm{TiO}_{2}$ with the corresponding samples to which water was added, it can be observed that, in all cases, the addition of water shortens the time $t_{0}$, being clearly different for samples

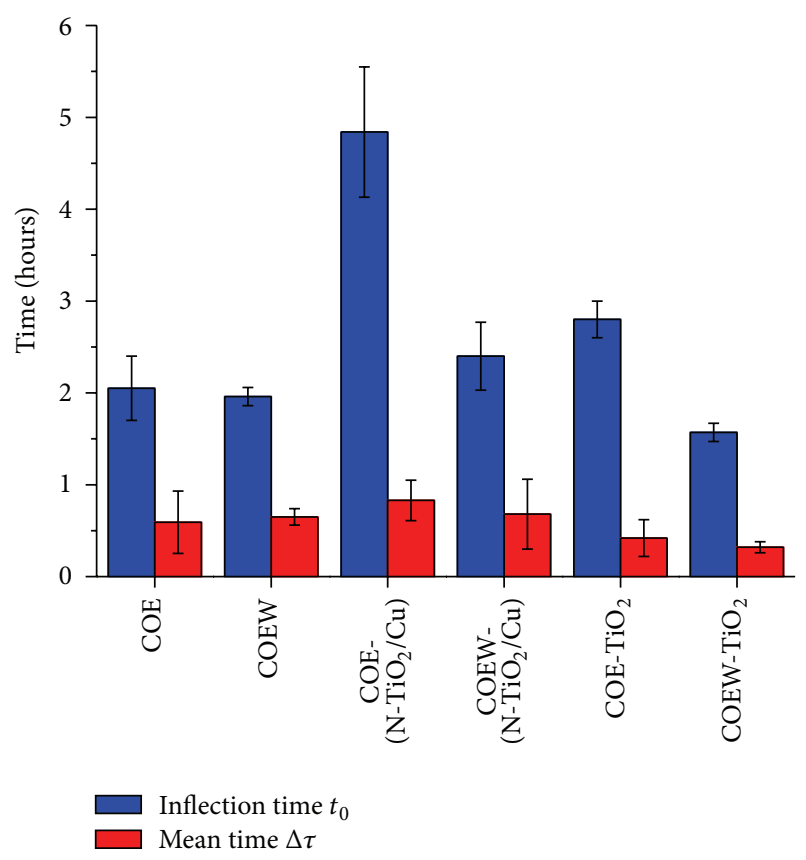

FIGURE 9: The time parameters of the logistic curve establishing the differences induced in the crude oil extracts by UV-Vis illumination.

with $\mathrm{N}-\mathrm{TiO}_{2} / \mathrm{Cu}$ and those with $\mathrm{TiO}_{2}$. This indicates that water shortens the time at which the photodegradation rate reaches its maximum. However, by analyzing the behavior of $\Delta \tau$, it can be observed that the total time it takes is very similar with or without water. Hence, for a given treatment, water shortens the time to initiate photodegradation but once this process is induced, the duration of this last stage for samples with or without water is very similar. As a consequence, the time $t_{0}$ mainly corresponds to an induction time.

On the other hand, comparing all the samples with the different treatments, $t_{0}$ is around 5 hours for COE$\left(\mathrm{N}-\mathrm{TiO}_{2} / \mathrm{Cu}\right)$ and 2.5 hours for $\mathrm{COE}-\mathrm{TiO}_{2}$, indicating that the presence of copper induces a delay in the initiation of the degradation. In contrast, $\Delta \tau$ is not very different for both types of samples, which indicates that once the photodegradation process starts, the duration of this last stage is similar for samples with $\mathrm{TiO}_{2}$ and $\mathrm{N}-\mathrm{TiO}_{2} / \mathrm{Cu}$.

This behavior can be a direct consequence of the fact that titania impregnated with copper has a stronger optical absorption in the UV; therefore, adding this material to the oil extract solutions could have the effect of obstructing partially the UV radiation, slowing down photolysis. On the other hand, the impregnation of titania with copper has shown diverse effects on the photocatalytic activity, when degrading methylene blue [12]. Even though the chemical processes induced by light are completely different for methylene blue and extracts of crude oil, our results agree with the ones previously found.

In particular, preliminary results obtained by us and others [20] indicate that a higher concentration of copper does not improve the photocatalytic properties of $\mathrm{Cu}-\mathrm{TiO}_{2}$; 
therefore, if the photodegradation of the porphyrins would be the objective, a possible solution could be to use nanoparticles with a lower content of copper concentration. Additionally, $t_{0}$ and $\Delta \tau$ are smaller for COEW- $-\mathrm{TiO}_{2}$ than for COEW samples. This implies that Degussa $\mathrm{P}-25 \mathrm{TiO}_{2}$ is showing photocatalytic activity in presence of water. In contrast, this is harder to observe in samples without water, where $t_{0}$ is 2 hours for $\mathrm{COE}-\mathrm{TiO}_{2}$ and 2.7 hours for COE; although there is a slight tendency for $\Delta \tau$ to being shorter for COE$\mathrm{TiO}_{2}$ than for COE, the spread in the values as represented by the error bars does not allow to unequivocally state that there is a difference between the values. Hence, it appears that direct absorption of UV-light by the crude oil extracts is capable of the photodegradation of petroporphyrins and that adding a $\mathrm{TiO}_{2}$-based catalyst, in the absence of water, does not significantly accelerate photodegradation. However, the presence of water results in a faster initiation of the photodegradation processes.

\section{Conclusions}

The effects of UV-Vis illumination on crude oil extracts containing petroporphyrins have been monitored as a function of time. Analysis of the UV-Vis spectra showed that the UVVis illumination induces the systematic reduction of the size of the $\alpha$ and $\beta$ bands, corresponding to the degradation of the petroporphyrins. It has been shown that this reduction can be parameterized as a second-order kinetics process. The analysis of the parameters of the degradation kinetics allows inferring that the addition of water to the crude oil extracts shortens the time to induce the photodegradation. However, once this process has initiated, the duration of the last stage of the photodegradation for samples with or without water is very similar. It has also been shown that the use of $\mathrm{N}-\mathrm{TiO}_{2} / \mathrm{Cu}$ induces an important delay in the initiation of the process of photodegradation of the porphyrins. Additionally, it has been shown that the presence of $\mathrm{TiO}_{2}$ in the samples extracted with water induces a small reduction in the duration of the photodegradation; hence, Degussa P-25 can catalyze the degradation of petroporphyrins.

\section{Conflict of Interests}

The authors declare that there is no conflict of interests regarding the publication of this paper.

\section{Acknowledgments}

Debra Jene Kirkconnell Reyes and Andrés García Saravia thank Conacyt for a scholarship. The authors wish to thank J. Ordoñez-Miranda, J. M. Yañez-Limón, C. Vales-Pinzón, D. Macías, J. Bante-Guerra, Gaspar Euan, N.W. Pech-May, and B.E. Heredia-Cervera for their useful suggestions and enlightening discussions during the development of this work. This work was partially funded by Conacyt projects 105816, 178510 and 193850 and FOMIX-Yucatán project 170120.

\section{References}

[1] IUPAC, Compendium of Chemical Terminology, The, "Gold Book", Blackwell Scientific Publications, Oxford, UK, 2nd edition, 1997.

[2] J. R. Payne and C. R. Phillips, "Photochemistry of petroleum in water," Environmental Science and Technology, vol. 19, no. 7, pp. 569-579, 1985.

[3] X. Xia, G. Li, Z. Yang, Y. Chen, and G. H. Huang, "Effects of fulvic acid concentration and origin on photodegradation of polycyclic aromatic hydrocarbons in aqueous solution: importance of active oxygen," Environmental Pollution, vol. 157, no. 4, pp. 1352-1359, 2009.

[4] T. Saeed, L. N. Ali, A. Al-Bloushi et al., "Effect of environmental factors on photodegradation of polycyclic aromatic hydrocarbons (PAHs) in the water-soluble fraction of Kuwait crude oil in seawater," Marine Environmental Research, vol. 72, no. 3, pp. 143-150, 2011.

[5] Z. Zhou, Z. Liu, and L. Guo, "Chemical evolution of Macondo crude oil during laboratory degradation as characterized by fluorescence EEMs and hydrocarbon composition," Marine Pollution Bulletin, vol. 66, pp. 164-175, 2013.

[6] R. L. Ziolli and W. F. Jardim, "Photochemical transformations of water-soluble fraction (WSF) of crude oil in marine waters. A comparison between photolysis and accelerated degradation with $\mathrm{TiO}_{2}$ using GC-MS and UVF," Journal of Photochemistry and Photobiology A, vol. 155, no. 1-3, pp. 243-252, 2003.

[7] H. W. Hagemann and A. Hollerbach, "The fluorescence behaviour of crude oils with respect to their thermal maturation and degradation," Organic Geochemistry, vol. 10, no. 1-3, pp. 473-480, 1986.

[8] J. M. E. Quirke, T. Dale, E. D. Britton, R. A. Yost, J. Trichet, and H. Belayouni, "Preliminary characterisation of porphyrins from the Gafsa Basin, Tunisia: evidence for metal-free benzo porphyrins from an immature sediment," Organic Geochemistry, vol. 15, no. 2, pp. 169-177, 1990.

[9] M. Espinosa Pena, A. Manjarréz, and A. Campero, "Distribution of vanadyl porphyrins in a Mexican offshore heavy crude oil," Fuel Processing Technology, vol. 46, no. 3, pp. 171-182, 1996.

[10] X. Chen and S. S. Mao, "Titanium dioxide nanomaterials: synthesis, properties, modifications and applications," Chemical Reviews, vol. 107, no. 7, pp. 2891-2959, 2007.

[11] M. J. García-Martínez, I. Da Riva, L. Canoira, J. F. Llamas, R. Alcántara, and J. L. R. Gallego, "Photodegradation of polycyclic aromatic hydrocarbons in fossil fuels catalysed by supported $\mathrm{TiO}_{2}$," Applied Catalysis B, vol. 67, no. 3-4, pp. 279-289, 2006.

[12] R. Trejo-Tzab, J. J. Alvarado-Gil, P. Quintana, and P. BartoloPérez, "N-doped $\mathrm{TiO}_{2}$ P25/Cu powder obtained using nitrogen $\left(\mathrm{N}_{2}\right)$ gas plasma," Catalysis Today, vol. 193, no. 1, pp. 179-185, 2012.

[13] P. Chen, Z. Xing, M. Liu, Z. Liao, and D. Huang, "Isolation of nine petroporphyrin biomarkers by reversed-phase highperformance liquid chromatography with coupled columns," Journal of Chromatography A, vol. 839, no. 1-2, pp. 239-245, 1999.

[14] J. Workman and J. R. . Neenah, "Applied Spectroscopy," in Optical Spectrometers, Kimberly-Clark Corporation, Analytical Science and Technology, Wisconsin, 1997.

[15] M. Prushan, "Absorption and Fluorescence Spectroscopy of Tetraphenylporphyrin and Metallo-Tetraphenylporphyrin," 2005, http://www.lasalle.edu/. 
[16] M. Gouterman, G. H. Wagnière, and L. C. Snyder, "Spectra of porphyrins. Part II. Four orbital model," Journal of Molecular Spectroscopy, vol. 11, no. 1-6, pp. 108-127, 1963.

[17] A. Ceulemans, W. Oldenhof, C. Görller-Walrand, and L. G. Vanquickenborne, "Gouterman's "four-orbital" model and the MCD spectra of high-symmetry metalloporphyrins," Journal of the American Chemical Society, vol. 108, no. 6, pp. 1155-1163, 1986.

[18] H. Xu, G. Que, D. Yu, and J. R. Lu, "Characterization of petroporphyrins using ultraviolet-visible spectroscopy and laser desorption ionization time-of-flight mass spectrometry," Energy and Fuels, vol. 19, no. 2, pp. 517-524, 2005.

[19] L. R. Milgrom, The Colours of Life: An Introduction to the Chemistry of Porphyrins and Related Compounds, Oxford University Press, 1997.

[20] B. Xin, P. Wang, D. Ding, J. Liu, Z. Ren, and H. Fu, "Effect of surface species on $\mathrm{Cu}-\mathrm{TiO}_{2}$ photocatalytic activity," Applied Surface Science, vol. 254, no. 9, pp. 2569-2574, 2008. 

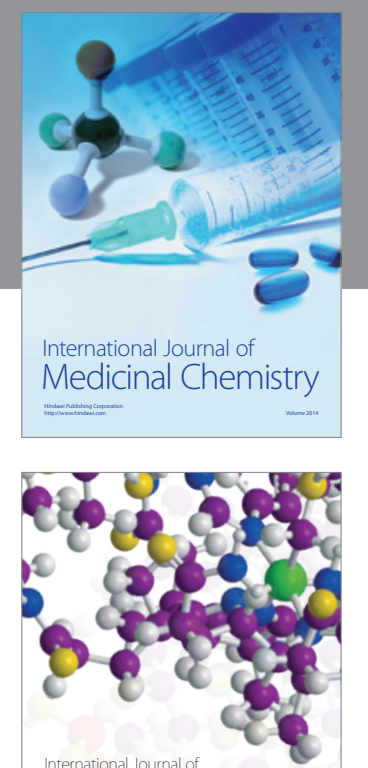

\section{Carbohydrate} Chemistry

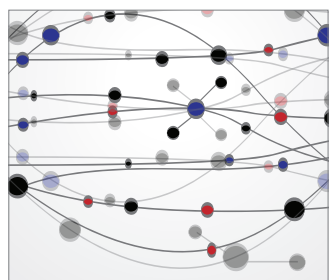

The Scientific World Journal
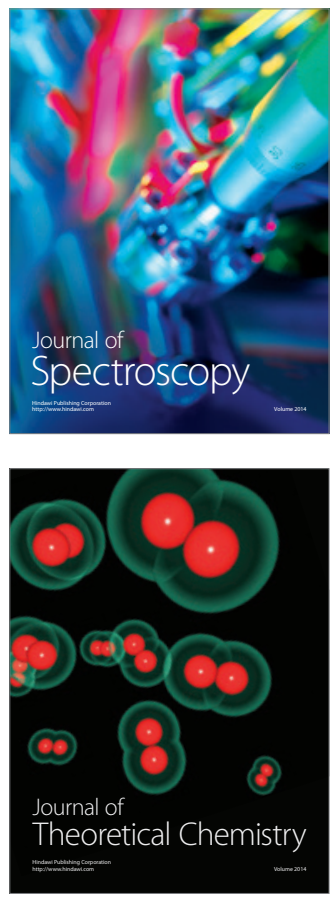
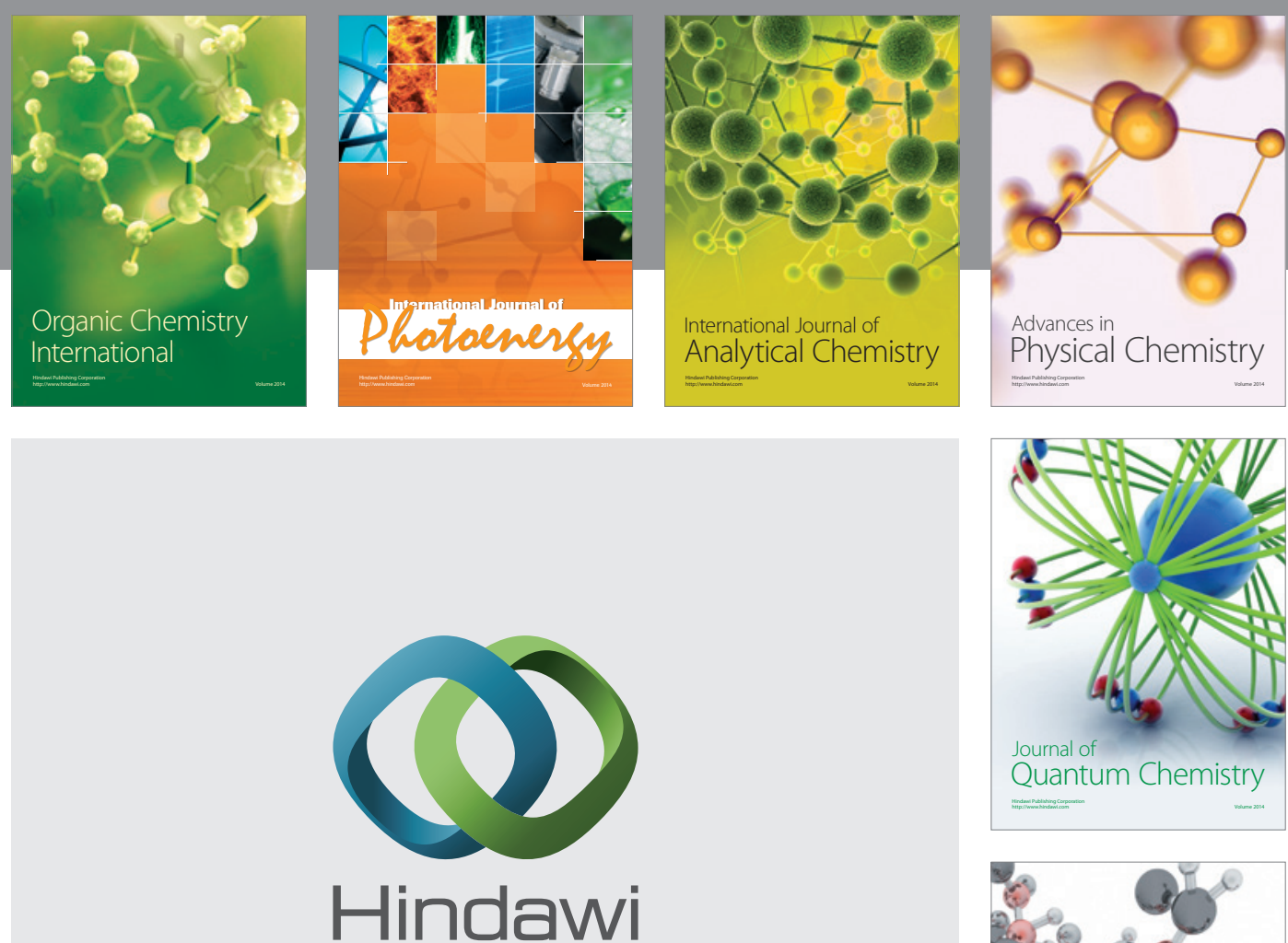

Submit your manuscripts at

http://www.hindawi.com

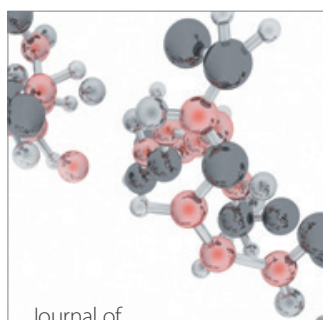

Analytical Methods

in Chemistry

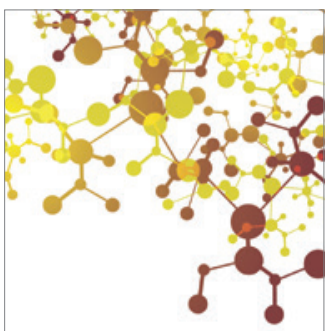

Journal of

Applied Chemistry

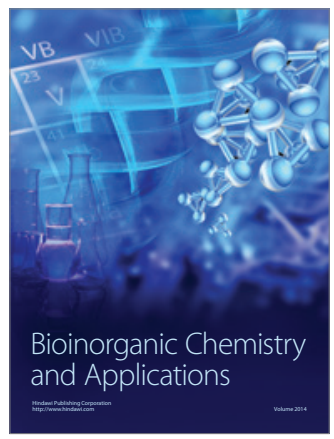

Inorganic Chemistry
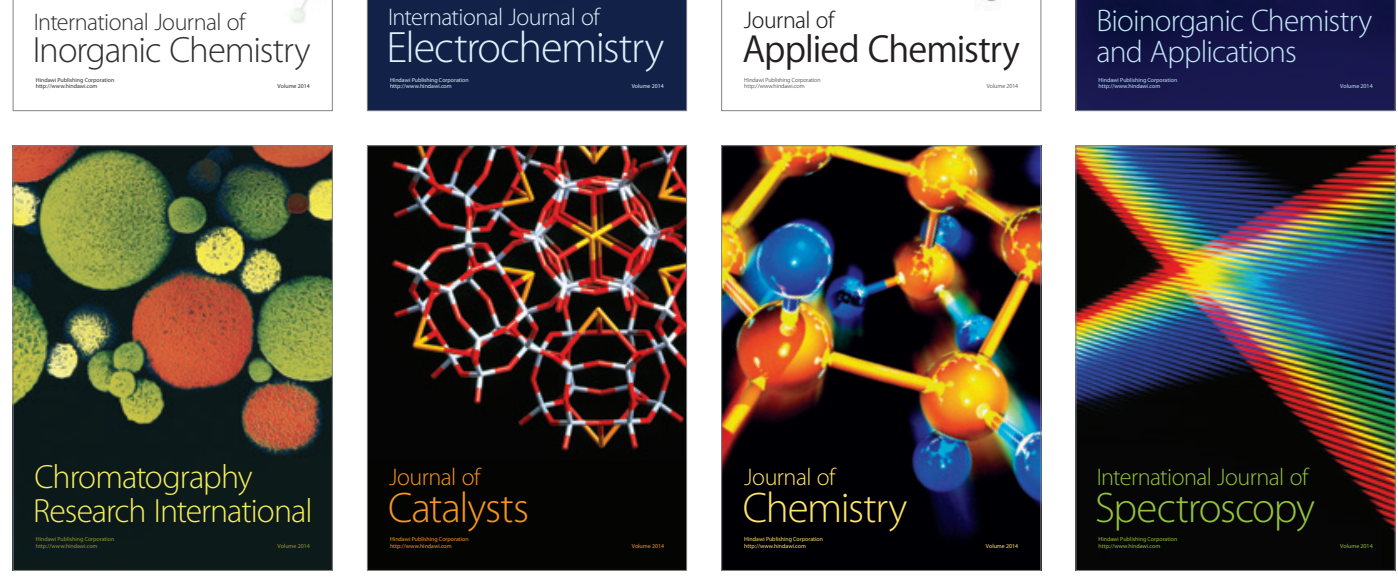